\title{
LIGANTE ATIVADO POR ÁLCALI À BASE DE CINZA VOLANTE E METACAULIM FLINT COMO MATERIAL DE REPARO PARA ESTRUTURAS DE CONCRETO ARMADO
}

\author{
RIBEIRO, RAFAELA CRISTINA ALVES \\ Graduação em Engenharia Civil \\ Instituto de Tecnologia da Universidade Federal do \\ Pará, FEC - GAEMA - ACGEO \\ Pará, Brasil \\ rafaelacristina.18@hotmail.com
}

\author{
BRITO, WOSHINGTON DA SILVA \\ Doutorando em Engenharia Civil \\ Instituto de Tecnologia da Universidade Federal do \\ Pará, PPGEC - FEC - ACGEO \\ Pará, Brasil \\ wsbrito3@gmail.com
}

\author{
GOMES-PIMENTEL, MAURÍLIO \\ Doutorando em Engenharia Civil \\ Instituto de Tecnologia da Universidade Federal do \\ Pará, PPGEC - FEC - GAEMA - ACGEO \\ Pará, Brasil \\ mauriliogpimentel@gmail.com
}

\author{
CAMPOS, PATRICK CORDEIRO \\ Graduação em Engenharia Civil \\ Instituto de Tecnologia da Universidade Federal do \\ Pará, FEC - GAEMA - ACGEO \\ Pará, Brasil \\ campospatrick777@gmail.com
}

\author{
SOUZA PICANÇO, MARCELO \\ Professor Doutor \\ Instituto de Tecnologia da Universidade Federal do \\ Pará, PPGEC - FEC - GAEMA - ACGEO \\ Pará, Brasil \\ marcelosp@ufpa.br
}

\section{RESUMO}

A exposição intensa das estruturas de concreto a situações inadequadas e ausência de manutenção podem conduzir a perigos potenciais, fazendo-se necessário ações de reforços e reparos para garantir a segurança e a durabilidade. No entanto, o impacto das soluções atualmente empregadas resulta na busca por opções mais sustentáveis. Este artigo relata a caracterização de um material álcali ativado à base de cinza volante e metacaulim Flint, a fim de inferir o seu potencial uso no reparo de estruturas de concreto. O estudo das propriedades reológicas e mecânicas sugerem que o ligante álcali ativado de cinza volante e metacaulim possui tempo de pega e resitências mecânicas adequadas para a aplicação em reparos rápidos em estruturas de concreto, sendo uma opção para os atuais materiais de reparo, além de representar uma solução socioeconômica e sustentável para os efeitos da cadeia de uma energia mais limpa e de custos adicionais na exploração mineral.

Palavras-chave: Cinza volante classe C, Álcali ativação, Caulim Flint;

\begin{abstract}
The intense exposure of concrete structures to inadequate situations and the absence of maintenance can lead to potential hazards, making reinforcement and repair actions necessary to ensure safety and durability. However, the impact of the solutions currently employed results in the search for more sustainable options. This article reports the characterization of an alkali material activated based on fly ash and metakaolin Flint, in order to infer its potential use in the repair of concrete structures. The study of rheological and mechanical properties suggest that the activated alkali binder of fly ash and metakaolin has a setting time and mechanical strengths suitable for application in quick repairs in concrete structures, being an option for current repair materials, in addition to representing a socioeconomic and sustainable solution for the effects of the cleaner energy chain and additional costs in mineral exploration.
\end{abstract}

Keywords: Fly ash class C, Alkali activated, Hard kaolin; 


\section{INTRODUÇÃO}

O concreto é o segundo material mais utilizado no mundo e um dos principais no cenário da construção civil, sendo o concreto armado responsável por tornar realidade as maiores empreitadas arquitetônicas da construção (BBC, 2018). Diante a ampla utilização do concreto, se durante a sua execução ou ao longo da sua vida útil não houverem manutenções e cuidados quanto ao uso adequado das edificações, este material pode ter a sua função e durabilidade afetada (GJORV, 2011). Nesse cenário, para garantir o bom desempenho das propriedades ao longo da vida útil do concreto uma das soluções aplicadas é a realização de reparos na estrutura, principalmente a concretos expostos em ambientes agressivos (GUO et al., 2020).

Para isso, diversos materiais já foram desenvolvidos e estão disponíveis atualmente no mercado, como é o caso dos cimentos modificados com polímero (PARK et al., 2012), concretos de fibra (TAYEH et al, 2013) e argamassas de reparo. Porém, apesar da disponibilidade de muitos materiais para reparo das estruturas de concreto, há pesquisas sobre o desevolvimento de novas opções mais sustentáveis para tal fim, por exemplo os ligantes álcalis ativados (HUSEIEN et al., 2018).

Os ligantes álcali ativados são materiais de baixa emissão de dióxido de carbono, em que dependendo do material precursor possui baixa porosidade e alta resistência, resultados da reação entre uma fonte de metal alcalino e um precursor rico em óxido de cálcio ou ainda um material aluminossilicato com maiores quantidades de alumina (PROVIS et al., 2014), entre os quais podemos citar a cinza volante e o metacaulim.

A combustão do carvão mineral nas indústrias para a produção de energia resulta em um resíduo denominado cinza volante gerada nas caldeiras do processo Bayer em condições de $900{ }^{\circ} \mathrm{C}$ e $120 \mathrm{KPa}$. (BRITO, 2018), o qual pode representar cerca de $80 \%$ dos subprodutos desse processo (TEMUUJIN et al., 2019). A composição química desse resíduo é dependente do carvão que a origina, mas que em sua maioria apresenta maiores quantidades de sílica, alumina, óxido de ferro e óxido de cálcio, sendo estes responsáveis por classificar a cinza volante em Classe $\mathrm{C}$ e Classe $\mathrm{F}$, segundo a ASTM-C-618 (American Society for Testing and Materials) (TEMUUJIN et al., 2019; BRITO, 2018). A cinza volante é um material constituído de particulas esféricas e finas de propriedades complexas com fases amorfas e cristalinas, sendo desejável a utilização conjunta de outro precursor como o metacaulim (XU et al., 2018; ZHANG et al., 2014).

O metacaulim é o produto do tratamento térmico do mineral caulim transformando-o em metacaulinita, a qual dependendo do local de extração pode ser classificado como Flint (CARNEIRO et al., 2003). Contudo, o caulim Flint por ser estéril, pelo seu elevado teor de impurezas de ferro e titânio torna-se improprio para a indústria de tintas e papel, representando um custo adicional no momento da extração do caulim soft (CARNEIRO et al., 2003; SANTOS et al., 2013). Porém, ao passar pelo processo de beneficiamento térmico e desagregação, esse material aluminossilicato de grande reatividade pode ser utilizado para a ativação de ligantes alcalinos (BRITO, 2018). Dessa maneira, a ativação alcalina de um binário composto de cinza volante e metacaulim Flint é uma possível opção, visto que ambos os materiais possuem características proprícias.

A formulação de álcalis ativados representam uma alternativa ambientalmente amigável e com características de reparo e durabilidade melhores quando comparado aos materiais a base de Cimento Portland (XU et al., 2018; GERALDO et al., 2018). Dessa forma, com intuito de conhecer e analisar as propriedades no estado fresco, no estado endurecido e aspectos relacionados ao desempenho referente a absorção de água, caracterizou-se um material álcali ativado de cinza volante e metacaulim flint, a fim de inferir o seu potencial uso no reparo de estruturas de concreto armado.

\section{MATERIAIS E MÉTODOS}

A ativação alcalina da cinza volante $(\mathrm{CV})$ e metacaulim flint (MKF) foi realizada utilizando silicato de sódio com módulo de sílica ( $\mathrm{Si} / \mathrm{Na}$ ) igual a 2,19, solução de hidróxido de sódio ( $\mathrm{NaOH} 12 \mathrm{M}$, pureza 98\%) e água de pH igual a $6 . \mathrm{O}$ silicato de sódio é constituído de $14,62 \%$ de $\mathrm{Na}_{2} \mathrm{O}$ e $32,54 \%$ de $\mathrm{SiO}_{2}$ e densidade em 1,57 g/ $\mathrm{cm}^{3}$. Além disso, a solução de $\mathrm{NaOH}$ foi preparada anteriormente a partir da dissolução em água do hidróxido de sódio em escama. A cinza volante $(\rho=2,49$ $\mathrm{g} / \mathrm{cm}^{3}$ ) é da refinaria de alumina Hydro Alunorte, no munícipio de Barcarena no estado do Pará. E o metacaulim Flint ( $\rho$ $=2,72 \mathrm{~g} / \mathrm{cm}^{3}$ ) utilizado foi obtido com o beneficiamento prévio do caulim duro (caulim Flint). Esse caulim tem origem na refinaria Imerys - Rio Capim S.A., no município de Ipixuna, localizada próxima às bacias cauliníticas do Rio Capim (Figura 1A), o qual a partir da extração do caulim macio (caulim soft) que é recoberto por uma camada desse caulim duro (caulim Flint) é considerado estéreo (Figura 1B) e depositado em uma área livre da mina sem aplicação tecnológica (Figura 1C e 1D). Ademais, a composição química dos precursores utilizados para a formulção do material álcali ativado 
é apresentado na Tabela 1. E para determinar a distribuição do tamanho das partículas e a composição mineralógia da cinza volante e do metacaulim Flint foi realizada a granulometria à laser e a difração de raios X, respectivamente.

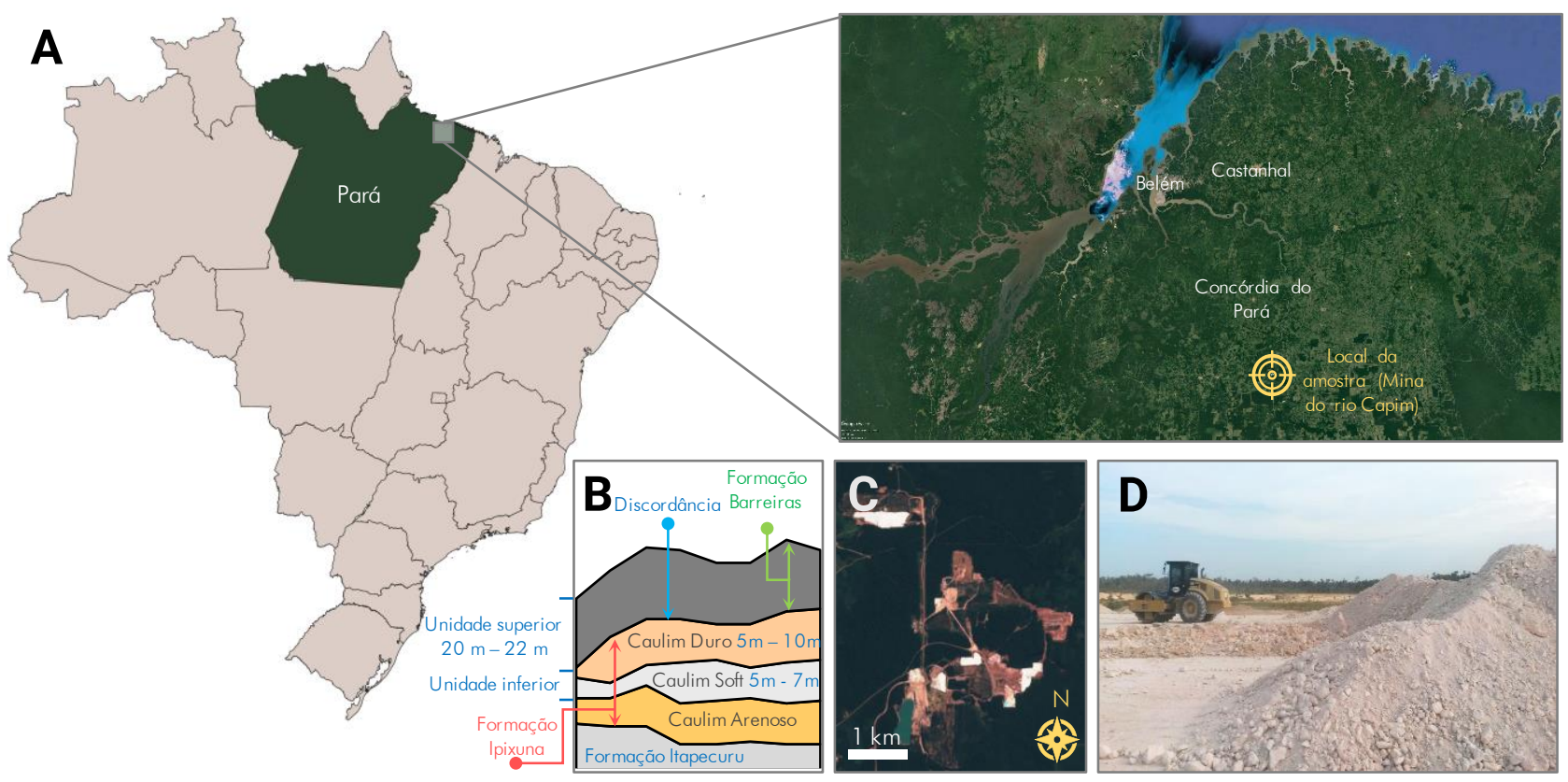

Figura 1: Localização da reserva de caulim no estado do Pará. A mina de caulim é localizada no nordeste do estado do Pará (A). Ilustração do perfil longitudinal das princiapis camadas argilosas (B). A ampliação da localização da amostra revela uma extensa área (região mais clara) de atividade de mineração (C). Deposito de caulim Flint (D). (A) Foto: Google Earth Pro, 13 de dezembro de 2015. (B) Imagem adaptada de Carneiro et al., 2003. (C) Foto: Sentinel 2, 20 de junho de 2019 do Sentinel Hub. (D) Foto: André Silva.

Tabela 1: Composição química da cinza volante e do metacaulim Flint obtidos a apatir da fluroescência de raios X (FRX).

\begin{tabular}{|c|c|c|c|c|c|c|c|c|c|}
\hline \multirow{2}{*}{ Material } & \multicolumn{9}{|c|}{ Composição química (\%) } \\
\hline & $\mathrm{SiO}_{2}$ & $\mathrm{Al}_{2} \mathrm{O}_{3}$ & $\mathrm{Fe}_{2} \mathrm{O}_{3}$ & $\mathrm{MgO}$ & $\mathrm{P}_{2} \mathrm{O}_{5}$ & $\mathrm{TiO}_{2}$ & $\mathrm{CaO}$ & $\mathrm{Na}_{2} \mathrm{O}$ & PF \\
\hline $\mathrm{CV}$ & 42,53 & 16,40 & 7,08 & 0,26 & 0,00 & 0,90 & 19,01 & 0,94 & 12,88 \\
\hline MKF & 43,89 & 38,97 & 1,38 & - & $<0,001$ & 1,29 & 0,01 & 0,13 & 14,46 \\
\hline
\end{tabular}

As pastas álcali ativadas foram produzidas com uma relação de $40 \%$ de cinza volante e $60 \%$ de metacaulim Flint como precursores, $21 \%$ de solução de hidróxido de sódio, $60 \%$ de silicato de sódio e $5 \%$ de água, esses percentuis são em relação a massa de cinza volante mais metacaulim Flint (CV+MKF). A relação $\mathrm{SiO}_{2} / \mathrm{Al}_{2} \mathrm{O}_{3}, \mathrm{SiO}_{2} / \mathrm{Na}_{2} \mathrm{O}$ e $\mathrm{Al}_{2} \mathrm{O}_{3} / \mathrm{Na}_{2} \mathrm{O}$ da mistura foi de 3,61, 3,99 e 1,10, respectivamente.

Incialmente, os materiais precursores foram homogenizados em um recipiente antes de serem adicionados no misturador mecânico. Então, foram adicionados a água, a solução de hidróxido de sódio e o silicato de sódio simultaneamente e realizada a mistura mecanizada desses materiais durante 2 minutos em velocidade baixa. Em seguida, parou-se o misturador por 30 segundos para retirada do material aderido no recipiente para melhor homogenização e, após isso, o misturador foi religado por mais 2 minutos em velocidade alta. Finalizado esse processo, moldou-se 3 primas (40x40x 160 $\mathrm{mm}$ ), os quais foram adensados em uma mesa de queda com 10 golpes após o preenchimento total de cada molde, depois as amostras foram cobertas com plástico PVA e colocadas na câmara térmica em cura por 28 dias, a temperatura de $35^{\circ} \mathrm{C}$.

Para a caracterização do material álcali ativado à base de cinza volante e metacaulim Flint foram realizados ensaios no estado plástico e no estado endurecido. Referente aos ensaios no estado plástico, o comportamento reológico do material foi estudado por meio do teste de consitência, colocando a pasta em um minicone sob uma mesa de queda previamente preparada com óleo desmoldante. Em seguida, levantou-se o cone lentamente, esperou-se 10 min e realizou-se as medições do diâmetro distribuido sobre a mesa. Bem como, para o avaliação do tempo de pega, colocou-se a pasta álcali ativada em um minicone e o posicionou no aprelho Vicat eletrônico previamente configurado e iniciado no momento em que os materiais entraram em contato durante o processo de mistura. Então, após 30 minutos da mistura da cinza volante 
e do metacaulim Flint com a água, o silicato de sódio e do hidróxido aconteceu o primeiro furo na pasta e, em intervalos de 2 minutos os seguintes 89 furos.

Quanto os ensaios no estado endurecido, para determinar a resistência à tração na flexão e a resistência à compressão axial as amostras primáticas foram ensaiadas de acordo com a NBR 13279 (ABNT, 2005). Além disso, para avaliar a absorção da pasta utilizou-se as metades dos três corpos de provas do ensaio de flexão e seguiu-se as orientações dadas pela NBR 9778 (ABNT, 2005) realizando algumas adaptações quanto ao tempo de fervura, o qual foi reduzido de $5 \mathrm{~h}$ para $1 \mathrm{~h}$.

\section{RESULTADOS E DISCUSSÃO}

A análise termogravimétrica do caulim Flint revela que existem duas reações que ocorrem em estreitas faixas de temperatura (Figura 2A), a primeira se refere a formação de metacaulinita no entorno de $540^{\circ} \mathrm{C}$ (CARNEIRO et al., 2003), a segunda é por conta da formação da mulita no entorno de $880^{\circ} \mathrm{C}$ (CARNEIRO et al., 2003). A perda de massa do material é iniciada na temperatura de $180^{\circ} \mathrm{C}$, ressalta-se que o material foi seco em estufa a $110^{\circ} \mathrm{C} \pm 5^{\circ} \mathrm{C}$ antes da análise termogravimétrica. A perda de massa total do material sugere que ele é composto com $89 \%$ de caulinita. Para transformar a caulinita em metacaulinita, o material foi calcinado em um forno mufla a temperatura de $800^{\circ} \mathrm{C}$ (Figura $2 \mathrm{~B}$ ), pois a perda de massa do material na análise termogravimétrica é estabilizada no entorno dessa faixa de temperatura. Após a calcinação o material passou por um processo de moagem em moinho de bolas.

O beneficiamento do caulim Flint permitiu que as partículas apresentassem um diâmetro médio de 121,2 $\mu \mathrm{m}$ (Figura 2C), superior ao da cinza volante que foi de 27,5 $\mu \mathrm{m}$. Além disso, as partículas de caulim Flint se concentram em duas estreitas faixas granulométricas, apresentando uma granulometria descontínua, já a granulometria a laser da cinza volante revela uma granulométrica contínua e bem graduada. A calcinação do caulim Flint permitiu que a caulinita fosse decomposta, apresentando um halo amorfo em $2 \theta$ entre $16^{\circ}$ e $25^{\circ}$ (Figura 2D). Já a cinza volante apresenta várias fases cristalinas, equanto o caulim Flint calcinado apresenta apenas a fase anatásio (\#PDF 00-021-1272). Essa transformação de fases no material favorece a produção de ligantes álcali ativados, além de implicar no ganho de resistência, uma vez que por meio do processo de calcinação há uma mudança na estrutura que antes era cristalina e, então passa a ser marjotariamente amorfa (PACHECO-TORGAL et al., 2015).

As características de consistência e tempo de pega (Figura 3) da pasta álcali ativada é essencialmente importante ao se tratar de materiais de reparo, pois tais propriedades estão relacionadas a trabalhabilidade, transporte e aplicação do material (KRAMAR et al., 2016). Dessa forma, para a pasta álcali ativada de cinza volante e metacaulim Flint, alcançouse uma consistência média de 111,70 $\pm 1,28 \mathrm{~mm}$ considerável um fluxo viável (Figura 3A). Além disso, a pasta apresentou um tempo de pega inicial de aproximadamente $1 \mathrm{~h}$ e meia (Figura 3B), o qual pode ser relevante para atividades que necessitem um menor tempo de realização do reparo (PACHECO-TORGAL et al., 2015). 
A

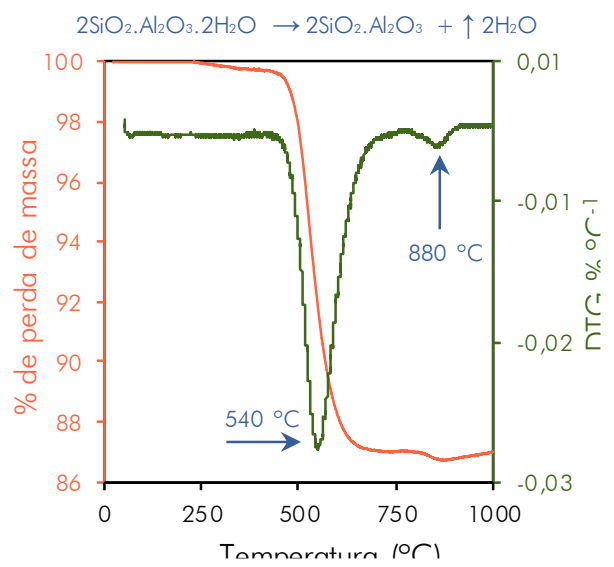

C

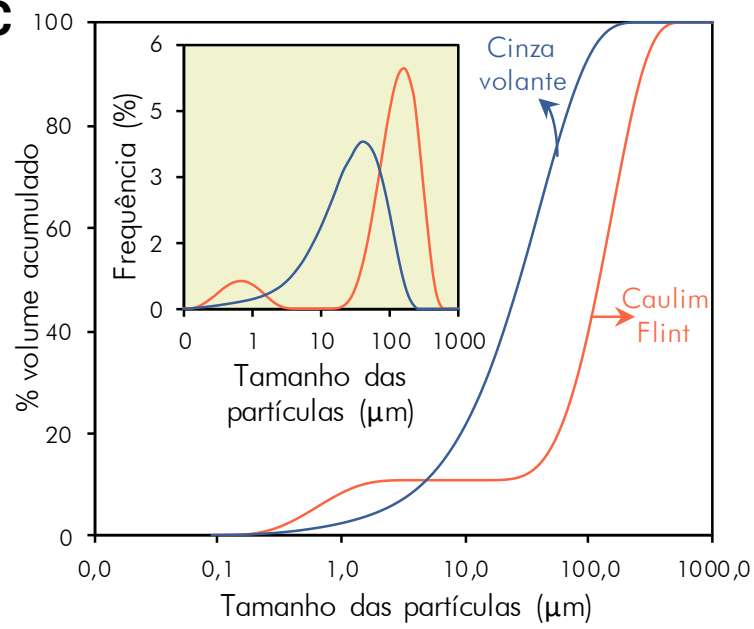

B

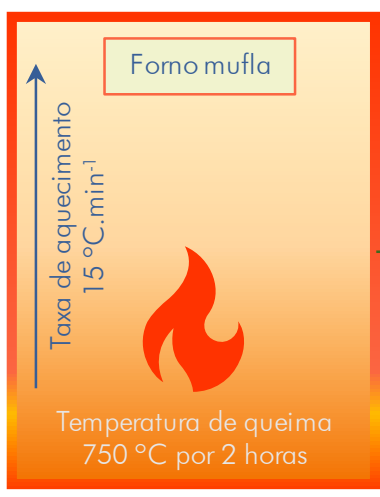

Moagem do metacaulim após a calcinação A proporção foi de

Kg de metacaulim : $10 \mathrm{Kg}$ de bolas $2 / 3$ de $\bigcirc \varnothing 20 \mathrm{~mm}: 1 / 3$ deo $\varnothing 12 \mathrm{~mm}$

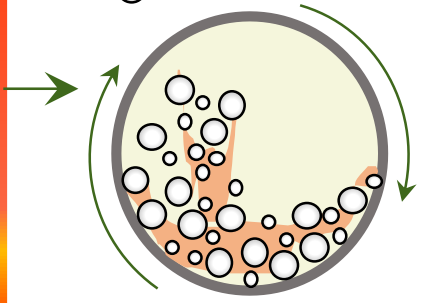

O tempo de moagem foi de 1 hora

D

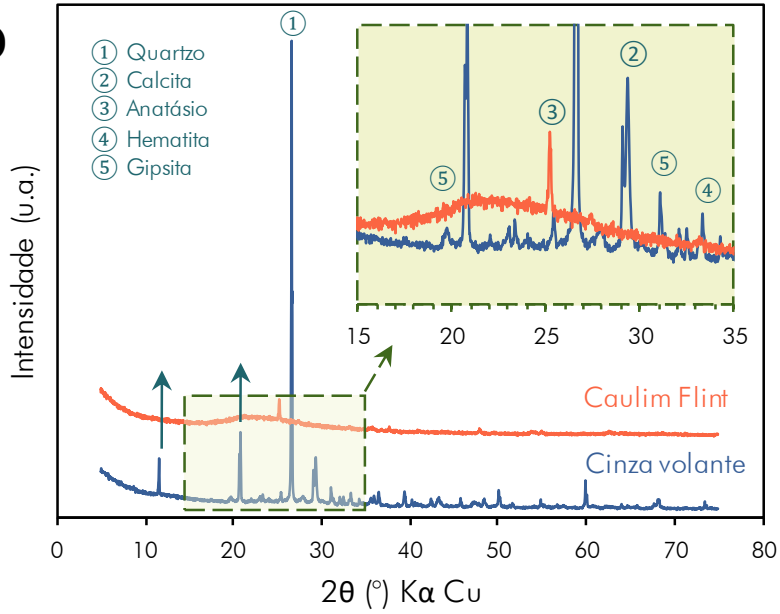

Figura 2. Beneficiamento e caracterização dos materiais: (A) análise termogravimétrica do caulim Flint para seleção da faixa da temperatura de calcinação. (B) ilustração e detalhes do processo de calcinação e moagem do material. (C) granulometria a laser da cinza volante e do metacaulim e (D) difratograma de raios $\mathrm{X}$ dos materiais revelando maior frequência de materiais cristalinos na cinza volante.

A

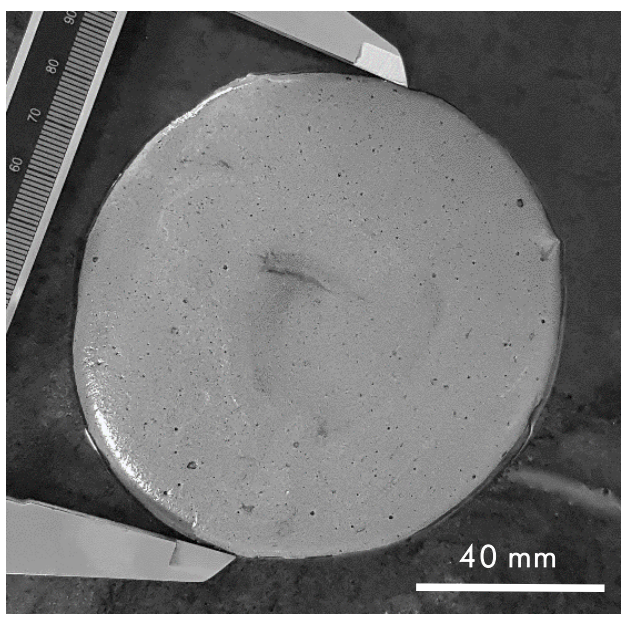

B

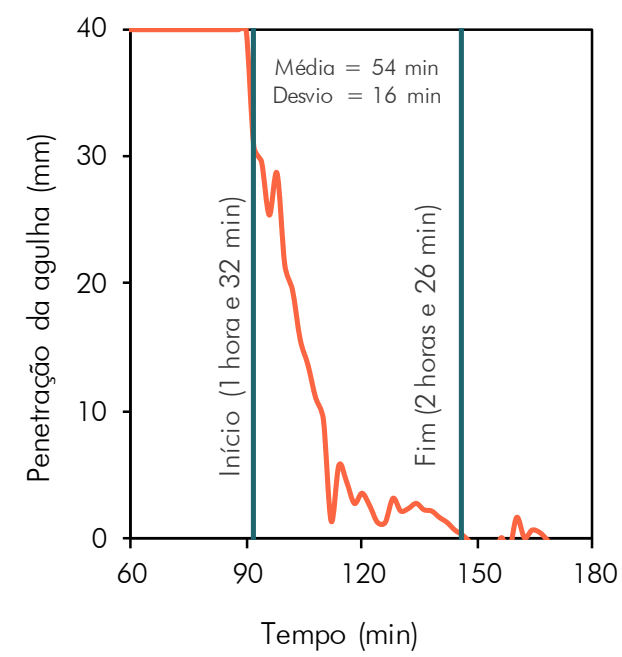

Figura 3: Reologia e tempo de pega do material. Em (A) a consistência da pasta do material álcali-ativado medida imediatamente após o tempo de mistura. (B) o tempo de pega do material inicia 92 minutos após a mistura e demora em média 54 minutos para finalizar.

O FTIR da amostra revela as bandas de vibração do material álcali ativado (Figura 4A). Os maiores picos que aparecem 
no espectro de absorção próximos a $3400 \mathrm{~cm}^{-1}$ e $1650 \mathrm{~cm}^{-1}$ indicam o alongamento e flexão, respectivamente, das moléculas de água (grupo H-O) (CHINDAPRASIRT et al., 2016; LEE et al.,2002; AZEVEDO et al., 2017; S. OLEJNIK et al., 1968). A formação da cadeia de aluminossilicatos é evidenciada por meio dos picos próximos a $1004 \mathrm{~cm}^{-1} \mathrm{referentes}$ ao alongamento assimétrico dos grupos Si-O-Al ou Si-O-Si (PERNÁ et al., 2019; SAMANTASINGHAR et al., 2018; LONGHI et al., 2020). Os cristais de quartzo são mostrados nos espectros relacionados às bandas $690 \mathrm{~cm}-1,570 \mathrm{~cm}-1$, 447 cm-1 associados alongamento de Si-O-Si (ZHANG et al., 2012). Ademais, os espectros relacionados a vibração de alongamento de O-C-O perto do pico $1460 \mathrm{~cm}^{-1}$ inferem a presença da calcita proveniente da cinza volante.

A análise de difração de raios X foi realizada na amostra antes da síntese e depois da síntese (Figura 4B), a fase gipsita que aparece na cinza volante não é identificada nas amostras tanto antes quanto depois da síntese. Os restantes das fases são conservados, por apresentarem estabilidade química. Na amostra antes da ativação alcalina o halo amorfo é localizado entre $2 \theta 15^{\circ}$ e $25^{\circ}$, após a ativação alcalina esse halo é delocado para o entorno de $2 \theta 28^{\circ}$. O pico de halo difuso da amostra pós síntese apresenta $2 \theta$ máximo em $27,72^{\circ}(3,215 \AA)$ e $29,06(3,070 \AA$ 丹 .
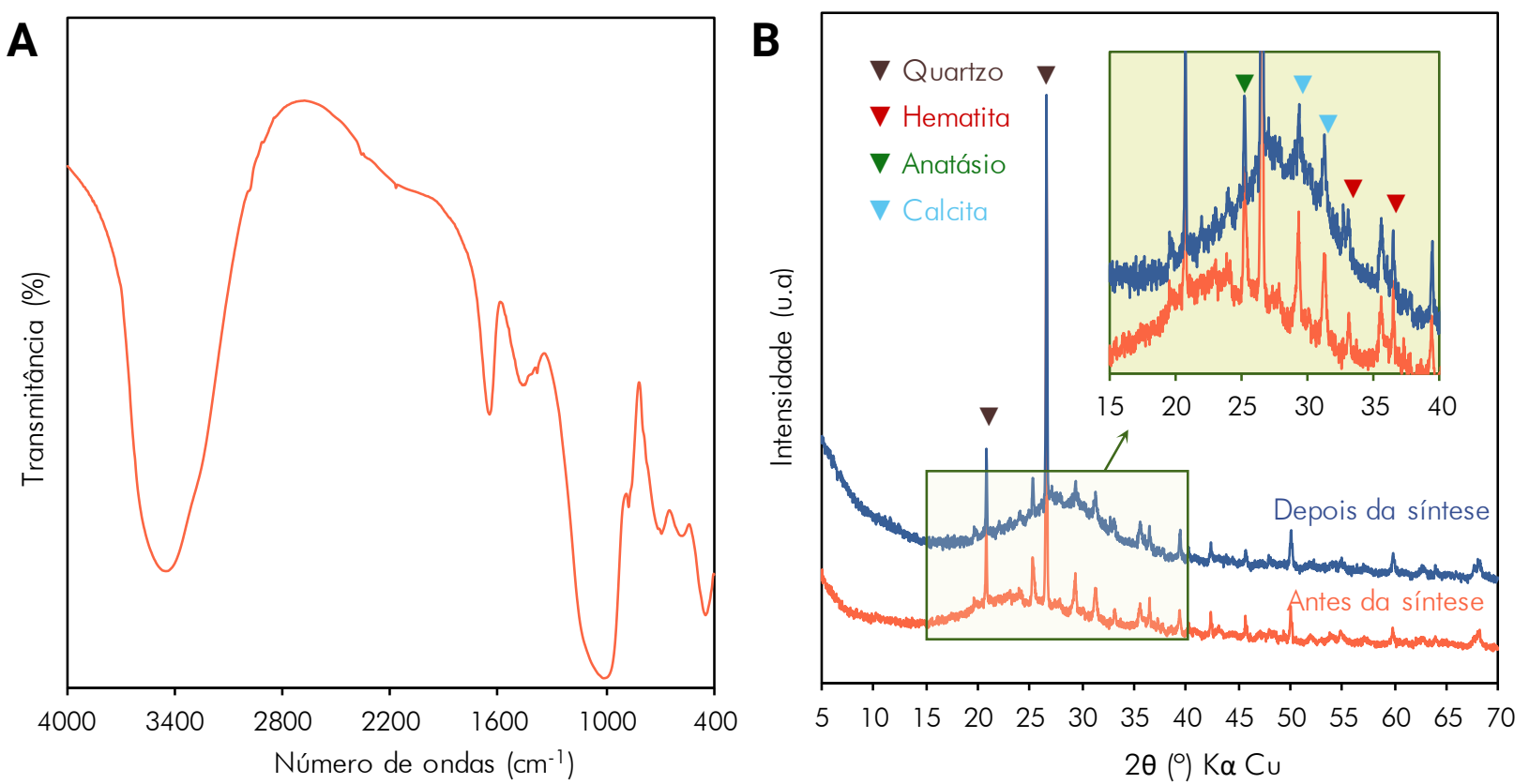

Figura 4: Microestrutura do material. Em (A) o espectro de FTIR da amostra e em (B) difratograma de raios X da amostra antes e depois da síntese, as fases cristalinas encontradas foram quartzo (\#PDF 01-078-1252), hematita (\#PDF 01-0730603), anatásio (\#PDF 00-021-1272) e calcita (\#PDF 00-005-0586)

Outra propriedade importante na caracterização do material é quanto a sua resistência, seja à compressão ou a flexão, pois determina quais aplicações praticas um certo material poderá ter (PACHECO-TORGAL et al., 2015). Portanto, avaliar o ligante álcali ativado de cinza volante e metacaulim Flint a partir dessas propriedades se faz necessário. O sistema binário de cinza volante e metacaulim Flint atingiu uma resistência média à compressão de 43,81 \pm 3,99 MPa e à tração de 5,28 $\pm 0,98 \mathrm{MPa}$, caracterizando o material, a partir dessas propriedades como adequado para o reparo, visto que tais valores são bem semelhantes aos materiais que normalmente são utilizados para reparo. Por exemplo, os grautes (TULA et al., 2003) ou ainda, as argamassas cimentícias com polímeros modificados, as quais possuem resistência à compressão e à flexão na faixa de 30 a $60 \mathrm{MPa}$ e 5 a $10 \mathrm{MPa}$, respectivamente (SILVA et al., 2001). Contudo, apesar da boa resistência, o álcali ativado de cinza volante e metacaulim Flint possui uma absorção média consideravelmente alta de 26,69\% quando comparado a esses mesmos materiais de reparo supracitados (SILVA et al., 2001).

\section{CONCLUSÃO}

A construção civil tem suas obras baseadas em um dos principais materiais utilizados no mundo, o concreto. Contudo, quando não executado ou não utilizado corretamente acaba necessitando por ações de reparo para garantir o bom desempenho da estrutura ao longo da sua vida útil. Nesse cenário, surgi os ligantes álcali ativados como alternativa sustentável e de baixo custo. 
Aqui caracterizou-se um material álcali ativado à base de cinza volante e metacaulim Flint, o qual apresentou propriedades favoráveis para o uso em reparo de estruturas de concreto. Primeiro, no estado fresco, o ligante possuí consistência e tempo de pega viável para reparos rápidos. Além disso, no estado endurecido, o álcali ativado atingiu resistências comparáveis a outros materiais atualmente utilizados.

Ademais, sabe-se que a utilização do carvão mineral para a produção alternativa de energia, apesar da boa intenção sustentável final, possui etapas não tão ambientalmente agradáveis devido aos resíduos que surgem no processo. O mesmo problema se propaga na extração de argilas cauliníticas como as de caulim soft no nordeste do estado do Pará. Esse processo possui um custo adicional com a retirada do caulim Flint que tem quantidades de ferro em sua composição que inviabiliza o uso na indústria de papel. Contudo, esses efeitos podem ser amenizados por meio da reutilização desses subprodutos inicialmente sem destinação específica. Dessa forma, os resultados apresentados a partir da caracterização de um material álcali ativado à base de cinza volante e metacaulim Flint contribui não somente para o campo da engenharia sendo utilizado como material de reparo para estrutura de concreto, como também representa uma solução socioeconômica e sustentável para os efeitos da cadeia de uma energia mais limpa e de custos adicionais na exploração do mineral caulim.

\section{AGRADECIMENTO}

Agradecemos ao Laboratório de Engenharia Química e Laboratório de Engenharia Mecânica da UFPA pelo auxílio no processo de calcinação do caulim Flint, ao Museu de Geociências da UFPA pela ajuda nas análises química e de granulometria, bem como pela realização da análise termogravimétrica, pelo FTIR e DRX da amostra. Gostaríamos de agradecer ao Laboratório de Engenharia Civil pela disponibilidade dos equipamentos para a realização dos ensaios de tempo de pega, resistência à compressão e à flexão e absorção de água. Além disso, agradecemos às empresas Hydro Alunorte e Imeyers pela doação do caulim Flint e da cinza volante, respectivamente. E reconhecemos o apoio da PróReitória de Pesquisa e Pós-Graduação da UFPA pelo fornecimento de bolsas de pesquisa por meio do Programa Institucional de Bolsas de Iniciação Científica. Ademais, aos integrantes do grupo de pesquisa Avanço na Ciência do Geopolímero (ACGeo), agradecemos as contribuições e críticas compartilhadas durante a construção desse trabalho.

\section{REFERÊNCIAS}

AZEVEDO, A. G. de S. et al. Produção de geopolímeros à base de cinza volante usando soluções ativadoras com diferentes composições de $\mathrm{Na}_{2} \mathrm{O}$ e $\mathrm{Na}_{2} \mathrm{SiO}_{3}$. Cerâmica, [s. l.], v. 63, p. 143-151, 2017.

BBC NEWS. Aquecimento global: a gigantesca fonte de $\mathrm{CO}_{2}$ que está por toda parte, mas você talvez não saiba. Disponível em: 〈https://www.bbc.com/portuguese/geral-46591753>. Acesso em: 14 dez. 2019.

BRITO, W. Ativação alcalina para a produção de geopolímeros a partir de resíduo industrial. 2018. Dissertação (Mestrado em Engenharia Química) - Universidade Federal do Pará, [S. 1.], 2018.

CARNEIRO, B. et al. Caracterização mineralógica e geoquímica e estudo das transformações de fase do caulim duro da região do Rio Capim, Pará. Cerâmica, [s. l.], v. 49, p. 237-244, 2003.

CHINDAPRASIRT, P. et al. Improvement of durability of cement pipe with high calcium fly ash geopolymer covering. Construction and Building Materials, [s. l.], v. 112, p. 956-961, 2016.

GERALDO, R. H. et al. Study of alkali-activated mortar used as conventional repair in reinforced concrete. Construction and Building Materials, v. 165, p. 914-919, 2018.

GJORV, O. E. Durability of concrete structure. Arabian Journal for Science and Engineering, v. 36, p. 151-172, 2011.

GUO, H. et al. Durability assessment of reinforced concrete structures considering global warming: A performancebased engineering and experimental approach. Construction and Building Materials, v. 233, 2020.

HUSEIEN, G. F. et al. Geopolymer mortars as sustainable repair material: A comprehensive review. Renewable and Sustainable Energy Reviews, v. 80, p. 54-74, 2017.

KRAMAR, S. et al. Assessment of alkali activated mortars based on different precursors with regard to their suitability for concrete repair. Construction and Building Materials, [s. 1.], v. 124, p. 937-944, 2016. 
LEE, W. K. W. et al. The effects of inorganic salt contamination on the strength and durability of geopolymers. Colloids and Surfaces A: Physicochemical and Engineering Aspects, [s. l.], v. 211, p. 115-126, 2002.

LONGHI, M. A. et al. Metakaolin-based geopolymers: Relation between formulation, physicochemical properties and efflorescence formation. Composites Part B: Engineering, [s. l.], v. 182, 2020.

OLEJNIK, S. et al. Infrared spectra of kaolin mineral-dimethyl sulfoxide complexes. The Journal of Physical Chemistry, [s. l.], v. 72, p. 241-249, 1968.

PACHECO-TORGAL, F. et al. Handbook of Alkali-activated Cements, Mortars and Concretes. Disponível em: $<$ https://books.google.com.br/books?hl=pt-

BR\&lr=\&id=KXQmBAAAQBAJ\&oi=fnd\&pg=PP1\&ots=FHyA1mg5T0\&sig=nXX1JQaeHAFkQLR3BUuRI8CSbg\&redir_esc=y\#v=onepage $\& q \& f=$ false $>$. Acesso em: 14 jan. 2020.

PARK, D. et al. Water absorption and constraint stress analysis of polymer-modified cement mortar used as a patch repair material. Construction and Building Materials, v. 28, p. 819-830, 2012.

PROVIS, J. et al. Alkali Activated Materials. [S. 1.]: RILEM State-of-the-Art Reports, 2014. v. 13. ISBN 9789400776715.

PERNÁ, I. et al. The synthesis and characterization of geopolymers based on metakaolin and high LOI straw ash. Construction and Building Materials, [s. l.], v. 228, 2019

SAMANTASINGHAR, S. et al. Effect of synthesis parameters on compressive strength of fly ash-slag blended geopolymer. Construction and Building Materials, [s. l.], v. 170, p. 225-234, 2018.

SANTOS, S. C. A. et al. Caulins amazônicos: possíveis materiais de referência. Cerâmica, [s. l.], v. 59, p. 431-441, 2013.

SILVA JR, J. Z. R. et al. Argamassas de reparo. Boletim Técnico da Escola Politécnica da USP. São Paulo, 2001.

TAYEH, B. A. et al. Evolution of Bond Strength between Normal Concrete Substrate and Ultra High Performance Fiber Concrete as a Repair Material. Procedia Engineering, v. 54, p. 554-563, 2013.

TEMUUJIN, J. et al. Processing and uses of fly ash addressing radioactivity (critical review). Chemosphere, v. 216 , p. 866-882, 2019.

TULA, L. et al. Grautes para reparo. Disponível em:

<https://www.researchgate.net/profile/Paulo_Helene/publication/242733633_GRAUTES_PARA_REPARO/links/55d4 7f5708ae0a3417246417/GRAUTES-PARA-REPARO.pdf.>. Acesso em: 14 jan. 2020.

XU, G. et al. Characteristics and applications of fly ash as a sustainable construction material: A state-of-the-art review. Resources, Conservation and Recycling, v. 136, p. 95-109, 2018.

ZHANG, Z. et al. Using fly ash to partially substitute metakaolin in geopolymer synthesis. Applied Clay Science, v. 88-89, p. 194-201, 2014.

ZHANG, Z. et al. Quantitative study of the reactivity of fly ash in geopolymerization by FTIR. Journal of Sustainable Cement-Based Materials, [s. l.], p. 154-166, 2012. 